\title{
FUNDAMENTOS CONCEPTUALES Y TEÓRICOS PARA MARCAS DE TERRITORIO'
}

\author{
Jordi de San Eugenio Vela \\ Departamento de Comunicación. Universidad de Vic \\ jordi.saneugenio@uvic.cat
}

\section{RESUMEN}

La competición de países, naciones, ciudades y regiones para captar recursos, talento, infraestructuras o eventos, entre otros aspectos, ha provocado el advenimiento de una lucha renovada por la singularidad, por el reconocimiento y por la diferenciación, por una hegemonía simbólica que cotiza al alza en el contexto de una emergente economía de la identidad. En este escenario, los espacios geográficos ceden sus proyecciones habituales de identidad territorial a una recién llegada identidad simbólica, gestionada, en parte, mediante la transformación de lugares en marcas. La concreción de algunos fundamentos teóricos y conceptuales a partir de los cuales determinar una propuesta epistemológica para marcas de territorio resulta ser el objetivo principal del presente trabajo.

Palabras clave: marca de territorio, marketing, branding, geografía, comunicación.

\begin{abstract}
The competition between countries, nations, cities and regions to attract resources, talent, infrastructures or events, among others aspects, has caused the coming of a renew struggle for singularity, recognition and differentiation, for a symbolic hegemony that is rising in the context of an emerging economy of identity. Indeed, places transfer their usual projections of place identity to a newly arrived symbolic identity negotiated partly by the transformation of places in brands. In this sense, the main aim of this paper is the concretion of some

Fecha de recepción: septiembre 2011.

Fecha de aceptación: enero 2013.

1 Este artículo incorpora parte de los resultados de investigación de la Tesis doctoral La transformación de territorios en marcas: el reconocimiento y la diferenciación de identidades espaciales en tiempos posmodernos. Un estado de la cuestión, dirigida por el Dr. Joan Nogué y por la Dra. Mònika Jiménez.
\end{abstract}


theoretical and conceptual foundations in order to determine an epistemological proposal for place brands.

Key words: place brand, marketing, branding, geography, communication.

\section{INTRODUCCIÓN}

La identidad, en un contexto de competitividad emergente entre territorios, resulta ser el elemento de reconocimiento, diferenciación y comercialización más importante en el proceso comunicativo de posicionamiento de ciudades, regiones y países. Los espacios, por tanto, compiten en base a la relación mantenida con esa misma identidad, la cual entra plenamente en una vorágine comparativa y competitiva (Nogué, 1999; Anholt, 2007a). Por lo tanto, la marca de territorio implica, fundamentalmente, una reinvención de los lugares a partir de un proceso de construcción de marca (branding) basado en la puesta en valor de las identidades individuales y colectivas de los espacios, que se imbuyen plenamente de los intangibles asociados a sus respectivas identidades territoriales.

El presente trabajo se articula en base a una propuesta de síntesis conceptual y teórica a partir de la cual alcanzar el objetivo principal del artículo que nos ocupa: establecer un estado de la cuestión referido a marcas de territorio. Este texto incorpora parte de los hallazgos de investigación más relevantes de la tesis doctoral presentada por el autor, resultado, en este caso, de una revisión crítica e interpretativa de la literatura referida a marcas vinculadas a espacios geográficos.

Los contenidos del artículo se organizan en función de una breve introducción que habilita un marco contextual (espacial y temporal) para marcas de territorio. A continuación, el texto propone una incursión hacia la definición e implicaciones de cuatro variables clave en el proceso de construcción y proyección de marcas territoriales: imagen, marca, identidad y autenticidad, para acabar concretando una definición en torno al concepto "marca de territorio'. Un breve recorrido histórico referido al nacimiento y a la evolución de la marca asociada a espacios geográficos precede a una propuesta de confrontación y/o comparación entre marcas corporativas y marcas espaciales. El trabajo continúa con la exposición de las características y objetivos fundamentales del branding de lugares, así como con la enumeración de los componentes (valores y/o atributos) principales que lo integran y le dan sentido. El desdoblamiento de la marca territorial y la concreción de sus particulares características en el espacio estatal y nacional, urbano y/o metropolitano y turístico, dará paso a la presentación de las conclusiones del texto de referencia.

\section{EL PUNTO DE PARTIDA: IMAGEN, MARCA, IDENTIDAD Y AUTENTICIDAD}

Para los intereses del presente artículo resulta muy útil establecer claras diferencias entre los conceptos 'marca' e 'imagen', a menudo erróneamente unificados. Del mismo modo, se incidirá, también, en el análisis de la tensión existente entre marca e imagen proyectada y percibida, que representa una de las fracturas (gaps) más importantes en el despliegue de una estrategia de construcción de marca de lugares. El concepto de identidad, ciertamente 
vinculado al de autenticidad en el marco de la contemporaneidad, cerrará la disposición de aspectos clave a partir de los cuales construir y gestionar una marca de territorio. Veámoslo a continuación.

\subsection{Imagen proyectada versus imagen percibida}

La imagen debe entenderse como la suma de creencias, ideas e impresiones que una persona tiene de un territorio, según manifiestan Crompton (1979) y Kotler, Haider y Rein (1994). Del mismo modo, la imagen de un lugar se concibe a modo de construcción mental y social, en base a los conocimientos, las impresiones y los valores que se acumulan de ese mismo espacio geográfico. Esencialmente, se acepta la existencia de dos tipologías de imagen territorial (Bramwell y Rawding, 1996; Galí y Donaire, 2003; Govers, Go y Kumar 2007; Stock, 2009; Camprubí, 2011): la emitida y la percibida. La imagen percibida se refiere a una percepción individual o grupal, acompañada de un proceso cognitivo a partir del cual se establece una visión y posterior valoración de un lugar. Por tanto, la imagen percibida se vincula al conjunto de creencias, impresiones y opiniones que sobre un territorio se instalan en la mente humana. En este punto, Galí y Donaire (2003, 2005 y 2006) señalan la existencia de tres tipologías de imágenes percibidas: a priori, que se corresponde con el universo mental de un individuo antes de su desplazamiento y contacto físico con el territorio objeto de viaje; in situ, que tiene lugar cuando se produce un análisis comparativo y de contraste entre la imagen imaginada previamente y la efectivamente vivida; y finalmente, $a$ posteriori, que se concreta en una nueva vivencia de la experiencia turística con posterioridad al viaje realizado.

Por su parte, la imagen emitida o bien inducida se produce mediante el uso del altavoz de variados canales de comunicación (mass media, relaciones públicas, internet) o bien de estrategias de marketing y/o branding con el fin de generar difusión, de crear un relato, una narración o bien un imaginario estratégicamente evocado a un público objetivo al cual se pretende mostrar una premeditada imagen de marca territorial. Galí y Donaire (2005) identifican la imagen emitida a modo de reproducción de signos con significado que ha sido socialmente construido y diseminado. Miossec (1977), en lo referido específicamente a imagen turística, identifica tres variantes de imagen emitida: en primer lugar la imagen universal, relacionada con arquetipos, estereotipos o imaginarios tradicionales de lugares fuertemente instalados en la mente humana; en segundo lugar las imágenes efímeras, que devienen particulares reinterpretaciones de la realidad a través del arte, la pintura, la literatura o los medios de comunicación, entre otras opciones; y en tercer y último lugar, las imágenes inducidas, que se corresponderían strictu sensu con una estrategia de branding territorial, objeto de interés principal de este artículo.

Otro aspecto interesante de tratar es la probable confusión entre la imagen y la marca de un destino, aspecto revisado por Tasci y Kozac (2006). El estudio de estos autores sostiene que la disposición de una imagen positiva surge como resultado de la obtención de una marca fuertemente anclada en el mercado. Por lo tanto, la marca es algo más que una imagen. Los autores, finalmente, ponen especial énfasis en la fractura existente entre la imagen proyectada (la carga de valores y atributos presentes en un territorio y transmitidos mediante una marca) y la imagen percibida (la percepción directa del consumidor al mantener contacto 
directo con la marca). He aquí una de las principales contribuciones del branding de territorios, concretada en la modulación del posible sesgo existente entre las expectativas generadas por la imagen proyectada a priori y las sensaciones experimentadas in situ. De este modo, y a través de un trabajo sostenido de construcción y proyección de marca de territorio (tanto en el nivel a priori como en el nivel in situ) se consigue atenuar la fractura perceptiva existente, así como elevar el grado de congruencia entre la imagen proyectada y la imagen percibida (San Eugenio, 2012).

\subsection{La marca en la actualidad: definición y funciones}

De Chernatony y Dall'Olmo Riley (1998), y Ollé y Riu (2009) expresan las ambigüedades y dificultades de definición para la acepción marca. La convergencia de múltiples definiciones y la inexistencia de una teoría de la marca -ausencia ya expresada por Semprini (1995) - dificultan su ubicación epistemológica, que debería producirse a partir de la concreción de los límites y los dominios que le son propios. Kapferer (1994) enfatiza el concepto de valor de marca, que vendrá determinado por la capacidad de la marca para conseguir un significado que resulte exclusivo, positivo y prominente en la mente de los consumidores. Para Riezebos (2003), la marca es una red de elementos de conocimiento instalados en la memoria a largo plazo. El núcleo que da sentido a esa red procede del nombre que se asigna a la marca, que está vinculado a otros conocimientos y significados. Efectivamente, la marca llega a convertirse en un constructo multidimensional caracterizado por un posicionamiento a medio camino entre los valores funcionales y emocionales de una organización y/o territorio -el añadido «territorio» es de cosecha propia- y las necesidades psicosociales de los consumidores (De Chernatony y Dall'Olmo Riley, 1998). Desde el punto de vista de los consumidores, uno de los conceptos más relevantes vinculados a la marca es el de imagen de marca. Para Dobni y Zinkhan (1990) -citados por De Chernatony y Dall'Olmo Riley (1998)-, la imagen de marca es un fenómeno de tipo subjetivo y perceptivo, formado mediante una interpretación razonada o emocional de la marca por parte del consumidor. En este nuevo milenio, el poder de las marcas ya no se justifica por lo que son, sino por lo que representa que son. Así es como, en el siglo XXI, numerosas y poderosas empresas han situado la seducción, las marcas y el branding en el centro de su mundo (Olins, 2004).

\subsection{Identidades contemporáneas y posmodernas}

Camprubí (2009: 79) sostiene que «la identidad de un lugar es un conjunto de elementos y atributos que singularizan a la sociedad que lo habita, entre los cuales destaca la historia, las tradiciones y la cultura, teniendo en cuenta que esa misma identidad se ha formado a partir de unos determinados procesos sociales». La relación entre identidad e imagen, que a menudo se manejan como términos sinónimos, se entiende por el componente de identificación del lugar que une a ambas acepciones. De este modo, y para el ámbito turístico, la percepción de la imagen turística viene acompañada en muchos casos de la interiorización de la identidad del destino (Camprubí, 2009). Por su parte, Cardús (2010) sostiene que la identidad, al fin y al cabo, no deja de ser un subterfugio que en realidad esconde una lucha simbólica por el reconocimiento y el poder. Se muestra, además, especialmente reticente 
con la visión reduccionista a la que la sociedad global ha sometido a la variable identidad al identificarla con algo sustantivo.

El mismo autor se muestra crítico también con la obsolescencia del significado históricamente atribuido a la expresión identidad nacional, víctima hoy de una promiscuidad cultural, de una movilidad internacional y de una fragmentación del espacio nacional sin precedentes. Los sentimientos ancestrales de pertenencia territorial y del tipismo propio de tiempos pasados son claramente transgredidos por el impacto, entre otros aspectos, de las Tecnologías de la Información y la Comunicación (TIC). En este punto, Cardús (2010) sostiene que la lucha por la identidad nacional se reduce al reconocimiento y a la diferenciación que en la actualidad se manifiesta, por ejemplo, en la producción de marcas de territorio, que alcanzan altos niveles de representatividad de los espacios geográficos. Esta lucha excesivamente premeditada y dirigida a la búsqueda del reconocimiento y la diferenciación hace que la identidad, de alguna forma, pase a ser «un contenedor más que un contenido; es más una forma que un fondo. La forma de la identidad es la parte reconocible e identificable, mientras que el fondo -sea lo que sea lo que lo constituye- es confuso y heterogéneo» (Cardús, 2010: 20).

De Uña y Villarino (2011: 259) manifiestan que «La definición, la representación y la difusión de una propuesta de identidad configuran en la actualidad un conjunto de procesos relevantes en el territorio tanto para identificar como para generar diversas potencialidades de uso en el escenario global del turismo». Asimismo, se refieren a la necesidad de maximizar la experiencia cognitiva, emocional y recreativa con el destino turístico. Y en este punto definen lo que viene a ser una propuesta concreta de proyección contemporánea de identidad territorial (2011: 259): «La definición de una propuesta de identidad susceptible de ser representada por una narración del territorio». Y esa es, precisamente, la función encomendada a un ejercicio de branding de lugares, la de construir un discurso, una narrativa, un relato, un storytelling ${ }^{2}$ para el territorio que, además de fijar y proyectar su genuina identidad, permita a los espacios geográficos objeto de representación ser competitivos en un mercado global de lugares. Es así como la marca deviene una formalización simbólica y una representación de la identidad espacial contemporánea, donde la comunicación permite la identificación y el reconocimiento interno y externo del territorio (Nogué y San Eugenio, 2009; De Uña y Villarino, 2011).

«La identidad es una piel», afirma de nuevo Cardús (2010: 21), y ahora lo que importa no es preguntarse quiénes somos, sino afirmarse y distinguirse para evitar ser rechazados. Se impone, entonces, un pequeño artificio, en el que «se esconde más de lo que se muestra», señala el autor. En consecuencia, lo que se reafirma con fuerza es una economía de la identidad, surgida de una situación de competencia entre territorios, de la que saldrá vencedor aquel que demuestre tener más capacidad sustantiva. Una capacidad sustantiva que, en muchos casos, es aportada por los valores y/o atributos asociados a una marca de territorio, que dota de especificidad estable y permanente a un emplazamiento geográfico. Por tanto, la marca con incidencia espacial cumple dos funciones fundamentales: de dispositivo retórico y de eje vertebrador de un sistema de relaciones competitivas.

2 Se considera el arte de contar historias. Consiste en una de las técnicas más importantes para captar usuarios con el fin de que mantengan un vínculo emocional con una marca. El objetivo final se concreta en la consecución de lealtades con personas, marcas y territorios (el añadido territorios es propio). Fuente: http://www.masquecomunicacion.com/blog/2011/02/07/storytelling-el-poder-de-la-imaginacion/ 


\subsection{La autenticidad representada: ¿simulacro o realidad?}

El peregrino, convertido en viajero, busca con anhelo nuevos productos y emociones, busca una sensación de autenticidad (Prat y Cànoves, 2012). Lo realmente trascendente se centra en delimitar qué es auténtico e inauténtico, el original y la copia, en la actual sociedad posmoderna en la que nos encontramos (Nogué y Albet, 2007). El turismo deviene un excelente laboratorio de experimentación en este sentido (Eco, 1986; Wang, 1999; MacCannell, 2003; Urry, 2004; Garay y Cànoves, 2011). Wang (1999) se refiere a la búsqueda de una autenticidad simbólica, resultado de una construcción social, en detrimento de una autenticidad objetiva, entendida como la representación más fiel posible a la realidad existente.

Por tanto, la autenticidad no viene determinada por su dosis de realismo, sino por una percepción auténtica de los signos y símbolos que son consumidos por los usuarios. Ello implica una deconstrucción de la autenticidad, lo que supone concebir la inautenticidad manifiesta, el pastiche explícito, con total naturalidad. Estaríamos hablando, entonces, de una 'autenticidad teatral' (Cohen y Butler, 1995; Wang, 1999) o bien de una 'autenticidad representada' (MacCannell, 2003). Urry (2004) sostiene que la mirada turística está dispuesta a incorporar 'autenticidades' inducidas y representadas de forma consciente en nombre de su consumo y disfrute. Camprubí (2009) afirma que la autenticidad se sitúa a medio camino de la identidad (cómo somos) y de la imagen turística (cómo nos ven). La construcción de una marca territorial supone, en este sentido, un trabajo específico con la identidad de un lugar a partir de la cual proyectar una imagen que sea capaz de generar una ventaja comparativa y competitiva.

\section{DEFINICIONES EN TORNO AL CONCEPTO 'MARCA DE TERRITORIO’}

Las marcas asociadas a espacios geográficos figuran en la literatura con un carácter eminentemente confuso, poco estructurado, excesivamente disperso. Al problema inicial de la semántica y la terminología que relaciona espacios y marcas, cabe añadirle una dificultad de tipo idiomático. En todo caso, y en lo referido a este trabajo, se considerará la marca de territorio a modo de dispositivo aglutinador de los elementos diferenciales de un espacio geográfico, con el fin de lograr un determinado posicionamiento (López-Lita y Benlloch, 2005 y 2006). El proceso de revisión de la literatura relacionado con las marcas de lugares nos ha llevado al ámbito anglosajón prácticamente en un ochenta por ciento de los casos con respecto a la producción científica escrita relacionada con este ámbito de conocimiento. Ello nos ha permitido constatar que la escala geográfica y los significados políticos, sociales y económicos que se desprenden de las naciones, regiones, estados y otras entidades espaciales son diferentes en función del paradigma de conocimiento con el cual se afronte. Por ejemplo, tal y como señala Jenkins (2005) y para el ámbito anglosajón, el término 'espacio' se utiliza con connotaciones vinculadas a una determinada localización física (latitud, longitud, altitud), mientras que los términos 'lugar' y 'territorio' se usan en relación con unos determinados atributos físicos. En el mismo sentido, sostiene que 'lugar' (place, en inglés) representa la visión y a la vez la definición sociocultural del espacio. Del mismo modo, el término 'territorio' (territory, en inglés) mantiene relación con un contexto de gobernabilidad de un espacio, esto es, los límites de la nación-estado y, por lo tanto, asume un carácter 
relacionado con unas determinadas fronteras administrativas a partir de las cuales se concibe el territorio como una división geopolítica del espacio. El siguiente cuadro muestra los significados asociados a los términos espacio (space), lugar (place) y territorio (territory) en la esfera anglosajona:

Cuadro 1

LAS RELACIONES ENTRE ESPACIO, LUGAR Y TERRITORIO EN LAS DIFERENTES ESFERAS DEL CONOCIMIENTO Y LA PERCEPCIÓN DEL PARADIGMAANGLOSAJÓN

\begin{tabular}{|c|c|c|c|}
\hline $\begin{array}{c}\text { Dimensión } \\
\text { física }\end{array}$ & $\begin{array}{c}\text { Espacio } \\
\text { geontificación }\end{array}$ & $\begin{array}{c}\text { Lugar } \\
\text { significa }\end{array}$ & Territorio \\
\hline $\begin{array}{c}\text { Dimensión } \\
\text { económicales y }\end{array}$ & $\begin{array}{c}\text { Recursos naturales y } \\
\text { factores de distancia }\end{array}$ & $\begin{array}{c}\text { Factores } \\
\text { microeconómicos }\end{array}$ & $\begin{array}{c}\text { Cartografía } \\
\text { (impuestos, tarifas, } \\
\text { concentración } \\
\text { económica) }\end{array}$ \\
\hline $\begin{array}{c}\text { Dimensión } \\
\text { legal/política }\end{array}$ & & $\begin{array}{c}\text { Lealtades, aceptación } \\
\text { de la legitimidad } \\
\text { del régimen } \\
\text { gubernamental }\end{array}$ & $\begin{array}{c}\text { Límites } \\
\text { administrativos } \\
\text { y definición de } \\
\text { competencias y } \\
\text { poderes }\end{array}$ \\
\hline $\begin{array}{c}\text { Dimensión } \\
\text { sociocultural }\end{array}$ & & Identidad social & $\begin{array}{c}\text { Identidad «formal»o } \\
\text { administrativa }\end{array}$ \\
\hline
\end{tabular}

Fuente: Adaptado a partir de JENKINS, P. (2005): «Space, place and territory: An analytical framework», en Place identity, participation and planning (Hague, C. y Jenkins, P. Eds.). London, Routledge, 19-37.

En efecto, los significados asociados a los términos 'espacio', 'lugar' y 'territorio' en el ámbito anglosajón presentan numerosos matices en relación con el significado que estas mismas acepciones tienen en el ámbito europeo y estatal. Es por ello que hay que insistir en que, en el presente artículo, se tratará la marca de territorio desde un punto de vista holístico, tanto en lo referido a sus límites territoriales a cualquier escala como en lo que compete a sus connotaciones socioculturales, de intangibles o bien de significados geográficos que se le puedan asociar. El término anglosajón equivalente a la expresión 'marca de territorio' se corresponde con place brand (marca de lugar) o bien place branding (proceso de construcción de una marca de lugar). Sin embargo, no debe confundirse el concepto de marca de territorio (por ejemplo, 'Costa Brava' o 'Costa Dorada') con marcas que, a pesar de no disponer de una naturaleza esencialmente espacial, sí incorporan algún tipo de incidencia o connotación territorial (como es el caso, por ejemplo, de las marcas Futbol Club Barcelona (FCB) o Gamba de Palamós). 


\section{INICIOS Y EVOLUCIÓN DE LA MARCA ASOCIADA A ESPACIOS GEOGRÁFICOS}

Los orígenes de la marca de territorio son difíciles de ubicar en el tiempo. Esto es así porque en la delimitación temporal de las marcas de lugares hay dos referentes principales. Por un lado, hay que considerar el ejercicio de branding encubierto que las naciones y los países han llevado a cabo históricamente de una forma implícita. En opinión de Anholt (2008a), la vinculación entre marcas y territorios hay que situarla muchos años atrás, tal vez en la época de Alejandro Magno ( $356 \mathrm{aC}$ a $323 \mathrm{aC}$ ), quien fue de los primeros en entender que el éxito o el fracaso de los lugares dependía, en gran medida, de la imagen que proyectaban hacia el exterior. Los inicios documentados en la literatura referidos explícitamente al binomio marca-territorio -en el que la marca tiene un papel realmente importante y no puramente testimonial como ocurre en el ámbito de la promoción-, hay que situarlos a finales de los años ochenta y principios de los años noventa del siglo pasado, cuando autores como Bartels y Timmer publicaban en 1987 la obra City Marketing: instruments and effects. Asimismo, otros autores como Ashworth y Voogd daban a conocer su trabajo titulado Selling the City en 1990 y, posteriormente, en 1993 aparecía uno de los títulos de referencia en la vinculación entre marcas, marketing y territorios que existe en la literatura académica, se trata de Marketing places: attracting investment, industry, and tourism to cities, states, and nations, a cargo de Philip Kotler, Donald H. Haider y Irving Rein.

Las aportaciones iniciales de Kotler y otros autores han sido complementadas en etapas posteriores en el ámbito del branding por Morgan, Pritchard y Pride con su obra Destination Branding (2002). Destaca, de igual manera, la aparición de una edición especial dedicada al

Figura 1

EVOLUCIÓN RELACIONAL DE LAS ESTRUCTURAS DE COMUNICACIÓN DEL TERRITORIO MEDIANTE EL USO DE MARCAS

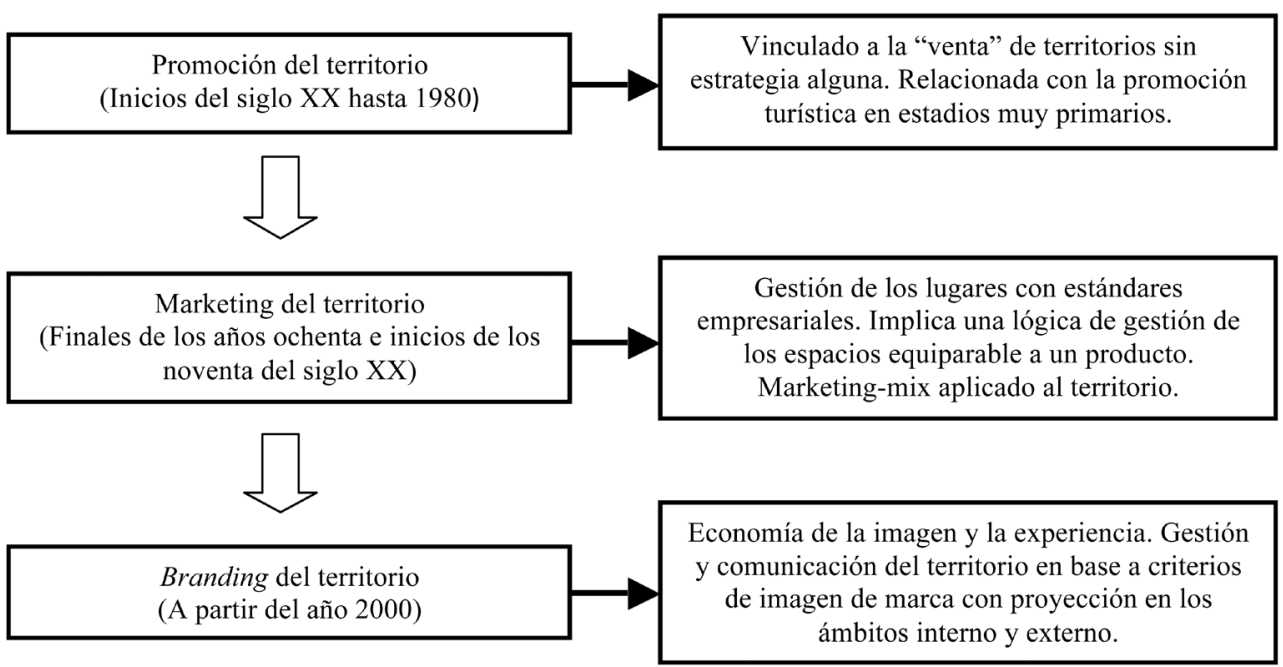

Fuente: Elaboración propia. 
country branding de la publicación Journal of Brand Management (2002), o bien la edición, en 2004, de la revista especializada Journal of Place Branding, actualmente denominada Journal of Place Branding and Public Diplomacy, editada por primera vez en el año 2005. De este modo, la vinculación inicial entre marketing y lugares ha derivado en la actual relación entre branding y espacios geográficos. Sin embargo, la revisión de la literatura señala para la dualidad marca-territorio unas relaciones realmente controvertidas. Esta dificultad se explica, sobre todo, por un rechazo sistemático a asociar territorios con marcas y con sus lógicas de actuación y producción.

El territorio y su comunicación ha experimentado una transición que ha partido de unos niveles iniciales de promoción (comunicar por comunicar, sin una estrategia de largo plazo concreta detrás y con el objetivo único de vender) hacia niveles de venta de lugares (muy vinculados a la publicidad y a la comercialización de la ciudad en términos de cultura). A continuación, ha seguido hacia estrategias de marketing (que implica la adopción de buena parte de las lógicas empresariales en la gestión y comunicación de espacios), para así terminar el recorrido donde estamos ahora: en la era del branding de lugares. Ello supone enfatizar la marca y su capacidad para diferenciar y posicionar a unos determinados espacios con el objetivo último de proyectar una imagen dirigida a públicos internos y externos, con el afán de captar no sólo turistas, sino talento, inversión empresarial, infraestructura, etc.

\section{DE LA MARCA COMERCIAL A LA MARCA TERRITORIAL}

El branding corporativo se consolida como el referente de aplicación en el ámbito de los territorios. El planteamiento de esta dicotomía -corporaciones versus territorios- en un contexto de branding permite desarrollar un análisis comparativo a partir del cual concretar las diferencias básicas de aplicación de un proceso de construcción de marca (branding) en ambos casos. Si bien los objetivos terminales de corporaciones y territorios convergen, el camino por recorrer es sustancialmente diferente. Los objetivos terminales, esto es, la obtención de una buena imagen y reputación, coinciden absolutamente. Las divergencias aparecen, sobre todo, por la naturaleza de dominio público inherente a los lugares. Por tanto, una primera diferencia se produce por la existencia de un ámbito de trabajo con implicaciones sociales totalmente diferentes, es decir, un ámbito de gestión política, de dominio y de bienes públicos (territorios) y un ámbito de gestión empresarial, y por lo tanto, de titularidad privada (corporaciones).

Vinculado a este mismo aspecto se encuentra el mapa de público interesado y de público implicado. El público interesado en una marca de territorio, ya sea de ciudad, país, región o destino, es absolutamente heterogéneo, lo que conlleva, sin duda, dificultades notables para diseñar una estrategia de marca que sea capaz de aglutinar y consensuar todo tipo de intereses ciudadanos. Además de eso, la sociedad civil se transforma, con especial énfasis, en un elemento activo de la marca, y desarrolla el rol de prosumer-intervención activa y directa en el proceso de creación de marca- tal como han demostrado en varias investigaciones Freire (2006) o Blichfeldt (2005). Por tanto, en una marca de lugar, las comunidades locales son, a la vez, emisoras y receptoras del proceso de branding. Emisoras porque uno de los elementos clave de la marca de territorio para la generación de imagen positiva in situ es el trato dispensado por la población autóctona a los visitantes (Freire, 2006). Y también receptoras porque 
uno de los públicos más importantes de una marca de territorio es el público interno (Olins, 1999 y 2004), es decir, los residentes y las empresas locales (Fernández-Cavia, 2011). Por tanto, la imposibilidad o la notable dificultad para controlar al público interesado e interviniente en una marca espacial es también relevante (Blichfeldt, 2005; Anholt, 2007b y 2010). Del mismo modo, las marcas de territorio no tienen propietarios y, por tanto, delimitan y coartan sus posibilidades de gestión con estándares tradicionales de marketing y branding. Es por ello que Blichfeldt (2005) sugiere que, en gran parte, una marca asociada a un espacio geográfico se convierte en inmanejable. La posibilidad de gestión de la marca se reduce aún más por la existencia del factor «poblaciones locales», esto es, la interacción de las comunidades autóctonas con la población foránea, lo que acaba creando también una determinada imagen de marca no controlable por parte de los gestores de marca. En este sentido, la sugerencia del autor se encamina a proponer la integración de los residentes en los estadios iniciales de creación de la marca, con el objetivo de definir conjuntamente sus valores y de integrarlos en la propia estrategia de marketing.

Además de todo lo expuesto, una marca de territorio debe trabajar también y de manera prioritaria con su público interno, un aspecto que a menudo no se suele producir en las marcas de corporaciones, que trabajan fundamentalmente para un público externo, para clientes potenciales y/o habituales. La naturaleza intangible y las particularidades asociadas al lugar, es decir, la venta de algo no material, fungible, es también una diferencia y una dificultad añadida al proceso de branding corporativo no vinculado a servicios, sino a espacios. Otra diferencia destacable en el ámbito de los lugares, precisamente por su naturaleza de bien público, se produce mediante el despliegue de una tipología de branding entendida a modo de gestión de intereses ciudadanos y, por tanto, con una vocación muy cercana al desarrollo local, mientras que en el ámbito corporativo, la gestión de branding se concibe en clave estrictamente mercantilista, esto es, con ánimo de lucro. Sin embargo, queda claro que los territorios y sus dirigentes también buscan la obtención de un rédito de imagen resultante de la ejecución de una estrategia de branding de lugares. En el mismo sentido, Hankinson (2004 y 2010) manifiesta alguna de las diferencias que las marcas de lugares mantienen con las marcas corporativas. Se concretan, a grandes rasgos, por la naturaleza experiencial de los lugares; por la discontinuidad existente entre el producto promocionado (a priori) y el producto consumido (in situ); finalmente, el autor se refiere a la amplia gama de públicos involucrada en la gestión y recepción de los parabienes asociados a una marca de lugar, lo que sin duda dificulta el diseño y ejecución de una estrategia de marca consistente.

Anholt (2007a y 2010), considera la variable temporal para explicar las diferencias existentes entre una estrategia de branding comercial y su equivalente en el ámbito de los lugares. En el contexto territorial, la posibilidad de obtener una identidad competitiva implica trabajar, necesariamente, en el largo plazo, mientras que la lógica corporativa suele tender, en la mayoría de los casos, al corto plazo, a la obtención de resultados inmediatos. En términos de gestión, el branding corporativo se refiere a una tarea simple y notablemente delimitada (ámbito de mercado), mientras que el branding de territorios compete a una gestión compleja (ámbito social). La complejidad inherente a la gestión del espacio geográfico se traslada, de este modo, a la gestión de su marca.

En cuanto al tipo de branding concreto a aplicar, la libertad de movimientos existente en el ámbito corporativo (normalmente se trabaja con productos comerciales que permiten 
una elasticidad en la elección y proyección de una determinada imagen) no se produce en el ámbito de los territorios. Habitualmente los lugares con los que se inicia un proceso de branding ya disponen desde sus inicios de una imagen predeterminada, resultado, probablemente, de viejos clichés y/o estereotipos anclados en el tiempo, con lo cual y a menudo en el ámbito de los territorios no procede un proceso de branding, sino un proceso de rebranding (Olins, 2002; Hankinson, 2004; Anholt, 2007b; Pasquinelli, 2010), es decir, deconstruir la imagen existente con el fin de adecuarla a los nuevos tiempos y a las nuevas necesidades del mercado.

\section{EL BRANDING DE LUGARES}

El proceso de construcción y proyección de una marca asociada a un espacio geográfico nos lleva a hablar de branding. En opinión de Fernández-Cavia (2011), este término se refiere a un proceso mediante el cual una organización (una empresa productora o de servicios, un partido político, una institución pública o un organismo gestor de un territorio) atribuye significado a la marca que representa. Así, hacer branding puede entenderse como construir valor de marca mediante la comunicación efectiva de los atributos que se quieran trasladar a la mente de los receptores. Por su parte, Monerris (2008) acota el término al ámbito específico de los lugares, afirmando que la aplicación de esta estrategia en el ámbito territorial implica una planificación a largo plazo, con la finalidad de construir y mantener una reputación regional o nacional distintiva, positiva y competitiva, tanto interna como externamente. Se consigue, según este autor, a través de una aproximación estratégica, armonizada y públicamente consciente a la innovación, la agenda pública, las relaciones externas, la promoción de inversiones, la exportación, el turismo y las relaciones culturales (Monerris, 2008). Para Solsona (2008: 269) la técnica de branding se identifica con «La capacidad de seducción, de comunicar a través de un símbolo o un lema las bondades de un destino, de despertar los sentidos del potencial usuario, de motivarle para satisfacer sus necesidades sociales, afectivas, emocionales, es decir, la capacidad de generar y gestionar una marca».

Sobre la base de un modelo fundamental de diferenciación y posicionamiento propios de la marca corporativa, y en líneas generales, el branding de territorios persigue los objetivos siguientes (Fernández-Cavia, 2011: 107): aumentar su atractivo como lugares de inversión empresarial; mejorar su posición competitiva en el mercado turístico; incrementar su atractivo con la finalidad de captar y retener el talento; fomentar la identificación de ciudadanos con su lugar de residencia; y finalmente, facilitar, en general, el desarrollo económico y social.

\subsection{Los componentes, valores y/o atributos de las marcas territoriales}

Huertas (2011), en lo que atañe al ámbito turístico, señala que los componentes de una marca se concretan en: el elemento gráfico (símbolo y logotipo); el componente conceptual funcional (que se vincula al logotipo y le añade la simbolización de las singularidades tangibles e intangibles de un territorio); y el componente conceptual emocional (que supone la anexión de valores abstractos, simbólicos y personificables a un destino). 
En lo referido al componente conceptual emocional de una marca territorial, Anholt y Hildreth (2004) definen el hexágono de la identidad competitiva de regiones, naciones, países y destinos turísticos, en función de la evaluación de seis variables fundamentales: el turismo, las marcas de exportación, las personas, la política interna y externa, la cultura y el patrimonio, la investigación y la inmigración. En función de los resultados obtenidos, se establecen rankings de países y de ciudades que ostentan una mejor posición en la arena mundial (The Anholt-GfK Roper City Brands Index ${ }^{3}$ y The Anholt-GfK Roper Nation Brands Index ${ }^{4}$ ). Del mismo modo, la consultoría Future Brand desarrolla anualmente y desde 2005 el estudio Country Brand Index 5 (CBI), encargado de evaluar la fortaleza de las marcas de país (113 naciones). Los atributos que utiliza esta empresa para clasificar las mejores imágenes de país proyectadas a escala mundial se corresponden con: sistema de valores (libertad política, tolerancia, marco legal estable, libertad de expresión y respeto al medioambiente); calidad de vida (mejor para vivir, educación, sistema de salud, estándar de vida, seguridad y oportunidades laborales); aptitud para los negocios (mano de obra cualificada, tecnología avanzada, clima de inversión y marco regulatorio); patrimonio y cultura (belleza natural, historia, arte y cultura y autenticidad); y finalmente se considera el turismo (conveniencia, hoteles y resorts, atracciones y gastronomía).

En todo caso, y en líneas generales, los indicadores más habituales en la definición del posicionamiento de una marca de territorio son los siguientes: identidad, cultura, capital humano e intelectual, patrimonio, tradiciones y eventos, clima, infraestructuras, recursos naturales, economía, historia, organización empresarial, geografía, urbanismo, arquitectura y paisaje, entre los ítems más importantes por considerar. Asimismo, se puede considerar que la suma de los atributos individuales que se acaban de enumerar surgen del desmembramiento de una variable fundamental: la identidad. Por tanto, se considera que la gestión y comunicación de la identidad, en el sentido más amplio del término, deviene el valor fundamental a partir del cual situar en ventaja competitiva y comparativa a una marca de territorio (San Eugenio, 2011).

\section{TIPOLOGÍAS Y FUNCIONES DE LAS MARCAS DE TERRITORIO}

En el ámbito concreto del branding de lugares, el objetivo de la marca -sostiene Anholt (2010) - no es exclusivamente el de obtener un rendimiento económico, sino que se pretende conseguir una buena reputación para el territorio, que, lógicamente, acabará repercutiendo en su prosperidad económica. La virtud de esta visión evolucionada de la marca destinada a actuar en el espacio geográfico radica, según este autor, en su flexibilidad, a tenor de su capacidad para unir las fuerzas del mercado con los intereses particulares del capital humano. En el mismo sentido se pronuncian López-Lita y Benlloch, al señalar lo siguiente (2006: 51): «La marca debe servir de base para 'marcar' los territorios en pro de la diferenciación y poder

3 Más información en:

http://www.gfkamerica.com/practice_areas/roper_pam/cbi/index.en.html

4 Más información en:

http://www.gfkamerica.com/practice_areas/roper_pam/nbi_index/index.en.html

5 Más información en:

http://www.futurebrand.com/wp-content/uploads/2011/11/2011-2012-FutureBrand-CBI-SPA.pdf 
así destacar las diferencias antropológicas y culturales transcendiendo su inicial dimensión estrictamente económica». Asimismo, Fernández-Cavia (2011) señala que la estrategia de branding se integra plenamente en un proceso global de desarrollo del territorio, en consonancia con una estrategia previa de marketing. Del mismo modo, su objetivo no se limita a proyectar y comunicar una determinada imagen y reputación hacia el exterior, sino que su rasgo diferencial se concreta en un trabajo específico con el público interno (población autóctona) en un intento de ensalzar el orgullo de residencia y el sentimiento de pertenencia a un determinado espacio. Veamos, a continuación, una propuesta de ordenación y atribución de significados y funciones para cada una de las tipologías existentes de marca de territorio.

\subsection{La marca de lugar en el espacio geográfico total (place brand)}

Anholt (2007c) mantiene que la aplicación de la lógica de marcas en los territorios tiene el objetivo fundamental de incorporar a los países, a las ciudades o a las naciones hacia un nuevo marco competitivo, un mercado global de lugares, donde los valores de una imagen diferenciada y positiva son fundamentales para destacar en un contexto de alta saturación entre territorios que luchan por obtener recursos económicos. Por lo tanto, sobre la base de una determinada imagen, la sociedad organiza sus decisiones de compra, inversión o cambio de residencia, además de elegir el destino turístico donde viajar (Kotler y Gertner, 2002). Para Papadopoulos (2004), el place branding pretende conseguir cuatro objetivos principales: mejorar la capacidad de exportación del país; proteger a las empresas y los negocios ya existentes en el territorio ante la llegada de posibles competidores externos; atraer o retener factores de desarrollo, y, finalmente, lograr un posicionamiento en los ámbitos interno (nacional) y externo (internacional) para conseguir una ventaja comparativa en términos económicos, políticos y sociales.

Govers y Go (2009) afirman que, ante todo, hay que deconstruir el antiguo modelo de place branding, muy vinculado a la teoría tradicional de la imagen de los lugares, la cual resulta inadecuada debido a la necesidad actual de vincular la imagen a los aspectos de identidad y comunicación de los territorios en un contexto global de espacio y tiempo. A diferencia de la promoción de los lugares, el branding espacial no es una actividad ejercida de manera intuitiva o al azar, sino que presenta un foco de actuación mucho más integrado y estratégico. Se vincula directamente con un nuevo estilo de vida de carácter urbano en el que las imágenes visuales y los mitos asociados al territorio adoptan una especial relevancia. En este contexto, la promoción de la imagen ocupa un rol central para planificadores y políticos. Por ello, la llegada del marketing y del branding a los lugares se convierte en una consecuencia natural de una nueva gobernanza del territorio muy orientada a satisfacer los deseos y anhelos de su público potencial (Kavaratzis, 2005 y 2011). Por tanto, el desdoblamiento definitivo entre los términos place promotion (promoción del lugar), place selling (venta del lugar) y place branding (construcción de marca de lugar) se produce a partir de la multiplicidad de públicos a los que dirigirse así como de atributos y valores que ofrecer.

En este sentido, Fernández-Cavia sostiene lo siguiente (2011: 103): «Desde mi punto de vista, la contribución más grande del marketing a la gestión de los territorios es haber introducido la convicción de que una ciudad, una región, una comunidad o un país tienen en la imagen que proyectan sobre el mundo su mayor activo, su mayor fuente de riqueza 
y bienestar. Y no se trata sólo de turismo, ni de economía, se trata de algo más general que afecta a todos los habitantes de este territorio, se trata de oportunidades y calidad de vida, en definitiva, de futuro».

\subsection{La marca en el espacio estatal y nacional (country/nation brand)}

De las definiciones que ofrece la Organización Mundial del Turismo (OMT), se desprende que la práctica del nation branding y el country branding se relaciona con una manifestación concreta de lo que es y lo que representa un país. En este sentido, la vinculación de estas dos tipologías de branding con la diplomacia pública y las relaciones internacionales parece mucho más clara que en otras manifestaciones de marca de territorio (Xifra, 2010). Por tanto, la proyección de una imagen positiva hacia el exterior -con lo que ello conllevase equipara a un ejercicio propio de una embajada, de la diplomacia o de una política de relaciones internacionales, con la consiguiente implicación de niveles de representatividad y de voluntad integradora de los activos de una entidad territorial plena, es decir, un país o una nación.

Asimismo, Anholt (2008b) señala la necesidad de establecer diferencias claras entre la promoción sectorial (turismo, exportaciones, promoción de la inversión, etc.) y el nation branding, que representa una estrategia totalizadora, unificada y representativa de los valores de una nación. Sin embargo, la práctica equiparación de países a la categoría de marcas es considerada por Anholt (2005b) un «mal menor necesario», máxime si se tiene en cuenta que en la sociedad actual, dotada de altos niveles de complejidad, la ciudadanía tiene la necesidad de simplificar el significado, la identidad y los valores asociados a una nación o a un país determinado, y esta reducción la ofrece únicamente la marca, transformada en el mundo actual en un dispositivo simplificador de niveles de complejidad social. En este contexto, el nation branding se convierte en una necesidad para los territorios que quieren competir en un mundo globalizado, además de contribuir a desprenderse de unos determinados estereotipos.

Esta visión es compartida por Dinnie (2008 y 2011), quien asegura que el branding de naciones, además de procurar la atracción de turistas, la estimulación de la inversión interna y el impulso de las exportaciones, entre otros aspectos, sitúa su foco de acción en el aumento de la estabilización de la moneda, el restablecimiento de la credibilidad internacional y la confianza de los inversores, el incremento de la influencia política, el fortalecimiento de las alianzas internacionales y, en general, en la mejora de la imagen de la nación en la arena mundial. Tal vez esta es la diferencia esencial entre el branding de naciones y/o países y el branding de unidades territoriales inferiores como los destinos, las ciudades o las regiones. Mientras que en el primer caso se imponen los intereses globales, de imagen atomizada, de representatividad transversal, en el segundo caso prevalecen intereses más de tipo sectorial, y, por tanto, su gestión se afronta desde un punto de vista más delimitado, menos totalizador de los intereses generales que sí se encuentran presentes en el nation branding o en el country branding.

En lo referido a la transposición del branding corporativo al branding de naciones, Holt (2004) -citado por Dinnie- mantiene que la transformación de marcas en iconos mediante un proceso de interacción creativa con su entorno es algo equiparable a un proceso de branding cultural, un concepto, por otra parte, especialmente adecuado en su aplicación a las naciones. 
En función de esta teoría, las naciones poseerían unos recursos concretados a modo de clúster estratégico de ideas culturales. En la misma línea, Rodríguez-Amat y Campalans (2010) señalan que en el proceso de creación de marca de país intervienen tres esferas diferenciadas: la lógica de mercado, la política y la identidad. En este sentido, el establecimiento de auténticas diferencias entre países se obtiene a partir del desarrollo de nuevas ideas, políticas, leyes, productos, servicios, etc. En definitiva, la construcción de una reputación sólida para países y naciones depende, casi de forma exclusiva, de la administración gubernamental del territorio y de su gente, y no del artificio propio de la promoción de sus productos y servicios.

\subsection{La marca en el espacio urbano y/o metropolitano (city brand)}

La necesidad de singularización inherente a la ciudad contemporánea y posindustrial se acaba concretando en un objetivo de posicionamiento distintivo, en una búsqueda de valor concreto para ofrecer a los «consumidores» reales y potenciales de la ciudad. Todas las acciones de marketing y branding de la urbe se dirigen hacia la tarea de proyectar, en los ámbitos interno y externo, una imagen positiva que facilite el logro de una reputación que permita a la ciudad competir en un escenario internacional. En este contexto, la marca se convierte en el activo principal de la metrópolis, en su máxima expresión de visibilidad y difusión de sus valores. Asimismo, la llegada de la globalización tiene un efecto territorial de dilución simbólica de las fronteras administrativas establecidas, lo que termina beneficiando a la ciudad, que se transforma en el motor de la competencia internacional, dado que pasa a ocupar una escala territorial dominante en la gestión operativa de servicios y personas propia del siglo XXI.

Además de eso, la competitividad de un territorio depende actualmente de su integración en los sistemas de información y comunicación globales. Y, precisamente, es esa competitividad sobrevenida entre ciudades lo que pone de manifiesto la necesidad de impulsar cambios en la organización y gestión pública de la urbe, sobre todo con el fin de alcanzar un determinado posicionamiento (Dinnie, 2011). En gran parte, la ciudad abandona su condición de clúster de relaciones económicas para convertirse en un sistema de símbolos que compite, básicamente, en el ámbito estético (Lash y Urry, 1998; Urry, 2004) para atraer talento, inversión e infraestructura, entre otros aspectos. La evolución de una ciudad de infraestructuras hacia una ciudad de valores, en la cual los aspectos inmateriales e intangibles tienen un protagonismo inusual, invita a una nueva gestión de las metrópolis contemporáneas, donde se vislumbra, claramente, la evolución del sector primario hacia el sector servicios y de la sociedad de la información.

Efectivamente, se produce un nuevo consumo de la ciudad contemporánea, una producción de nuevas identidades en un contexto de exaltación necesaria de la diferencia. Por tanto, la ciudad se convierte en el espacio de uso y consumo por excelencia, es decir, la transformación del espacio urbano y/o metropolitano en un producto de consumo cultural. La ciudad contemporánea es hoy uno de los espacios identitarios por excelencia del capitalismo tardío. La transformación de la ciudad se debe, en gran parte, a la reconceptualización de una vocación cultural y de conocimiento para el espacio urbano, que la sitúa en la punta de lanza territorial en todo lo referido a innovación y creatividad. 
Para Kavaratzis (2004), el branding de ciudades se convierte en la forma más adecuada para implantar y describir una estrategia de city marketing, ya que el objetivo del marketing de ciudades se centra, entre otros aspectos, en lograr una determinada imagen urbana que, a la vez, se convierte en el punto de partida para desarrollar una marca de ciudad. Para este autor, el branding de ciudades proporciona, por un lado, los fundamentos para la implantación de políticas de desarrollo económico, y, por el otro, sirve de hilo conductor para que los residentes se identifiquen con su propia ciudad.

Evans (2003) afirma que en las ciudades tiene lugar un proceso de hard branding (branding duro) a partir del cual se manifiesta la emergencia de un espacio urbano que se debe vivir en primera persona. Así, la experiencia con la ciudad permitirá dar salida a un renovado deseo fetiche de la sociedad vinculada a la avidez de consumo de una nueva metrópolis cultural, que aglutina, como nunca había sucedido antes, una dimensión experiencial y de entretenimiento muy cercana a experiencias temáticas del tipo Walt Disney World o Asterixland. En este punto, el mismo autor anuncia la llegada de los espacios marca. De este modo, se utiliza el poder cultural de la ciudad para crear una determinada imagen.

El branding urbano duro de tipo cultural referido por Evans tiene que ver con la unión de tres aspectos fundamentales: el fetichismo del consumo trasladado a la metrópolis, la explosión de la economía del simbolismo y, finalmente, la necesidad de dar salida a un anhelo emergente de consumo de espacios. Por su parte, Anholt (2007a) mantiene que el branding de ciudades permite un trabajo más concreto con los valores del territorio, un aspecto fundamental en la delimitación de atributos de marca que no se produce en el nation branding o en el country branding. Es en este sentido que la representatividad y el imaginario de un país proviene, en muchas ocasiones, del ámbito urbano y/o metropolitano. De hecho, la transición del marketing estratégico (determinación del valor de la ciudad que se ofrece al público interesado) al marketing operativo (creación y comunicación del valor de la ciudad) para llegar finalmente al branding de ciudades, se produce por el énfasis depositado en la marca, que se convierte en el dispositivo por antonomasia a partir del cual identificar y diferenciar los valores de la metrópolis. Por tanto, toda la simbología inherente a la urbe se canaliza mediante la marca, que se consolida a modo de importante activo intangible de la ciudad sobre la que giran la mayor parte de los procesos de comunicación urbana y/o metropolitana.

\subsection{La marca en el espacio turístico (destination brand)}

Anholt (2005b) mantiene que el turismo es a menudo el aspecto promocional más visible en el proceso de nation branding. Ello es debido a que la actividad turística acumula un amplio bagaje en aspectos vinculados a la comercialización de territorios, y esta circunstancia incide, por ejemplo, en la presencia de numerosa literatura relacionada con la promoción, el marketing y el branding de espacios turísticos. En el mismo sentido se pronuncian Rodríguez-Amat y Campalans (2010), cuando señalan que el turismo se convierte en un mecanismo catalizador y concentrador de lo cultural y lo simbólico, como interfaz de presentación de lo interior hacia el exterior. Además de eso, la experiencia profesional que une marketing y turismo también acumula un amplio recorrido, que se concreta, por ejemplo, en la existencia ya histórica de Organizaciones de Marketing de Destinos (OMD). Por tanto, el turismo se posiciona como eje central de los procesos que relacionan imagen, marca y territorio. Además, la actividad 
turística y su imagen asociada han resultado, históricamente, un gran mirador de los valores de un espacio geográfico (ya sea país, nación, región, ciudad, etc.), en positivo y en negativo. En efecto, el espacio turístico se consolida a modo de importante carta de presentación de un lugar, y la imagen que se le asocia proviene, probablemente, de una experiencia turística vivida en primera persona o de la fijación de una determinada imagen a partir de un ejercicio de promoción turística llevado a cabo en el pasado. En este sentido, Anholt (2005a) va más lejos al señalar que la práctica de branding de destinos provoca, en algunos casos, un efecto distorsionador de las percepciones de un país (entendido como proyección de una imagen atomizada, global, no exclusiva de los intereses turísticos), dado que está claramente enfocado a la venta de un destino turístico. Por su parte, MacCannell (2003), Urry (2004) y Donaire (2012) se refieren a la importancia del turismo desde un punto de vista sociológico, a partir de la llegada de una nueva industria de la imagen -de la mirada, según Urry- y de la experiencia que genera nuevos paradigmas de reflexividad estética ya anticipada por Lash y Urry (1998). El consumo contemporáneo, transportado al ámbito de los espacios, busca impetuosamente el placer estético, simbólico, semiótico. En este punto, el turismo resulta ser, de nuevo, la actividad paradigmática (Urry, 2004).

En opinión de Cai (2002), la expresión destination branding se refiere al proceso de selección de elementos consistentes de la marca a fin de identificar y distinguir un destino turístico mediante la creación de una imagen positiva. Morgan, Pritchard y Pride (2002) y Park y Petrick (2006) sostienen que la aplicación de lógicas de branding en espacios turísticos significa la habilitación de uno de los argumentos del marketing contemporáneo más eficientes al servicio de los gestores de destinos. Blain, Levy y Ritchie (2005) señalan que la ejecución de un proceso de destination branding debe priorizar los conceptos vinculados a identificación, diferenciación, experiencia, expectación, imagen, consolidación y refuerzo, a los que hay que añadir los inputs propios que se derivan de la misma gestión de los destinos, en concreto: reconocimiento, consistencia, mensaje vinculado a la marca y respuesta emocional.

Baker (2007) concluye su discurso referido a marcas y branding de destinos asegurando que el valor de la marca se construye a partir de cada punto de contacto con los clientes, mediante experiencias excepcionales y no sólo con el apoyo de las características físicas de los lugares. Cada experiencia, antes, durante y después de la visita, tiene un papel fundamental en la definición y entrega de la promesa inherente a la marca. En este sentido, el éxito de la marca vendrá determinado por el cumplimiento de las expectativas evocadas en un nivel inicial de comunicación. Finalmente, hay muchos autores que afirman que el branding de destinos es el más cercano a las lógicas de actuación del branding corporativo (Morgan, Pritchard y Pride, 2002; Cai, 2002; Olins, 2004; Blain et al. 2005; Anholt, 2009), ya que se ocupa de un sector productivo concreto (el turismo) y de un producto en particular (las vacaciones). Por lo tanto, este tipo de branding se concibe más en clave empresarial -vinculado a la industria del turismo, sus productos y servicios- que en clave territorial. Sin embargo, Anholt (2002) y Morgan, Pritchard y Pride (2002) coinciden en afirmar que una marca de destino no se corresponde con la marca de un producto - no se trata de vender sopa en polvo, en palabras de los mismos autores- y, por tanto, requiere de una aplicación responsable de los principios del branding corporativo y del marketing tradicional de lugares. 


\section{CONCLUSIONES}

Las marcas de territorio se definen, ante todo, por la influencia que ejercen en la percepción de los individuos. En este sentido, la fijación de una identidad singular concretada mediante una marca ofrece reconocimiento y diferenciación para determinados espacios geográficos, favoreciendo así un posicionamiento ventajoso que, a su vez, se convierte en decisivo ante las preferencias de elección de los usuarios. Además, una marca de territorio implica, simultáneamente, gestión y comunicación. Gestión no sólo con implicaciones de marca (brand management), sino también a partir de una renovada intervención en el territorio basada en criterios de marca y, en último término, de marketing. Por tanto, la gestión se encuentra fuertemente arraigada al marketing, mientras que la comunicación de la marca de territorio se vincula al branding. Las diferencias más representativas entre una marca de territorio y una marca comercial surgen, preferentemente, de las connotaciones de dinamización económica vinculadas a la implantación de marcas de lugares. Las implicaciones sociales (marca espacial) en contraposición a los intereses de mercado (marca comercial) son una constatación más de las divergencias conceptuales y de ejecución existentes entre estas dos tipologías de marca. Asimismo, todas las expresiones vinculadas a territorios y marcas parten de una cuestión esencialista: la asociación que se establece entre los lugares y la implementación de estrategias de comunicación que los sitúen en situación de ventaja comparativa y competitiva. No obstante, existe una importante falta de consenso en la definición del término «marca de territorio» desde un punto de vista holístico y transversal. Ello provoca que, en muchas ocasiones, por desconocimiento de las posibilidades que la marca puede ofrecer a un lugar en lo referido a gestión y proyección de su imagen, se acabe limitando su aportación al diseño de un logotipo o a la concreción de un eslogan, que no son per se, una marca territorial.

Una marca de territorio debe dar salida fehaciente a tres objetivos principales (por este orden): posicionamiento, sentimiento de pertenencia y adscripción por parte de las comunidades locales y, finalmente, debe ejercer a modo de dispositivo generador de percepciones positivas del territorio objeto de representación. Además de eso, la identidad resulta ser el elemento de singularidad por excelencia de un territorio. La cultura, el capital humano e intelectual, el patrimonio o la historia, son algunos de los atributos más importantes de identidad territorial a partir de los cuales posicionar con valor añadido a una marca de territorio. En clave de futuro, la marca representativa de lugares se convertirá en un activo irrenunciable para la atracción de inversiones, talento, infraestructuras, empresas o eventos, entre otras cosas. Aún así, es necesario destacar que una marca de territorio no implica, necesariamente, ningún tipo de manufactura. En muchos casos, la marca ya existe en el territorio de forma implícita, tácita, latente y, por tanto, en estos casos, las tareas exclusivas asociadas a la marca se corresponden con las funciones de visibilidad y proyección de una realidad ya existente.

La identidad de los territorios no es hoy una cuestión menor. Actualmente, se trata de algo cercano a la supervivencia, no tanto por una cuestión mercantilista, como por una manifiesta y necesaria exaltación de la identidad en tiempos de globalización. Esta reivindicación identitaria se puede canalizar, en parte, mediante un uso evolucionado del concepto tradicional de marca. Por tanto, hacer marca, o bien construir una marca (branding) no implica, en 
ningún caso, la tematización del territorio, sino que supone una indagación y una posterior puesta en valor de sus raíces identitarias.

Las marcas de lugares alcanzan, actualmente, uno de los máximos niveles de representatividad de los territorios. De este modo, se entiende su progresiva vinculación con estrategias de diplomacia pública (Xifra, 2009 y 2010). Además, la etapa contemporánea posmoderna y global que hoy vivimos, hace preponderante la economía de la identidad, la imagen y el simbolismo. En este contexto, los territorios, a menudo, son sometidos a un proceso de coacción simbólica con el fin de construir imaginarios ficticios y cosméticos en favor de la competitividad, lo que acaba generando, en algunos casos, la producción de marcas de territorio franquicia, de espaldas a la identidad que los singulariza. Por ello, y en general, la dinámica de implantación de marcas de territorio es esencialmente operativa (hacer) y poco reflexiva (saber hacer).

A lo largo de este trabajo, también se ha podido constatar que la implantación y gestión de marcas de lugares merece una reflexión más profunda referida a su valor de uso y cambio, el cual va mucho más allá de una simple campaña de promoción, para pasar a ser, de facto, una propuesta de desarrollo territorial y, por extensión, de mejora de la calidad de vida de los ciudadanos. Sin embargo, se confirma que este proyecto que se pretende de gestión transversal del territorio, se afronta habitualmente desde un monopolio disciplinario preocupante (comercialización e investigación de mercados), que no se corresponde con la naturaleza heterogénea del espacio geográfico y, en este sentido, parece imprescindible la entrada en escena de otras aportaciones disciplinarias (especialmente las relacionadas más directamente con el estudio del entorno geográfico). De igual forma, se considera indispensable afrontar los procesos de construcción y gestión de marcas de lugares desde una óptica y una lectura territorial, con el fin de evitar lo que algunos ya denominan como «la esclavitud de la marca» o la brandificación ${ }^{6}$ del territorio (Muñoz, 2008), es decir, la sumisión de la intervención y de la efectiva acción sobre el espacio geográfico en función de los 'designios de la marca', ocupada fundamentalmente en proyectar una determinada imagen en positivo a nivel interno y externo.

\section{BIBLIOGRAFÍA}

ANHOLT, S. (2010): Places: Identity, image and reputation. Hampshire. Palgrave Macmillan.

ANHOLT, S. (2009): «Introductory essay: Why nacional image matters» en Handbook on tourism destination branding (World Tourism Organisation., ed.). Madrid, Organización Mundial del Turismo, 9-16.

ANHOLT, S. (2008a): «Editorial». Place Branding and Public Diplomacy, vol. 4, $\mathrm{n}^{\circ} 2$, 97-101.

6 Muñoz (2008) se refiere a un proceso progresivo de brandificación del territorio, es decir, a la sumisión de los espacios geográficos a las necesidades de proyección de una determinada imagen. Se trata de la incidencia directa que sobre la ordenación del territorio y el planeamiento urbanístico tiene la obtención de unos determinados valores y/o atributos vinculados a la iconografía de los lugares. Para este autor la ciudad per se ya es una marca. 
ANHOLT, S. (2008b): «From nation branding to competitive identity. The role of brand management as a component of national policy», en Nation branding (Dinnie, K., ed.). Oxford, Butterworth-Heinemann, 22-23.

ANHOLT, S. (2007a): Competitive identity: The new brand management for nations, cities and regions. Basingstoke. Palgrave Macmillan.

ANHOLT, S. (2007b): «Editorial». Place Branding and Public Diplomacy, vol. 3, n 3, 191195.

ANHOLT, S. (2007c): «Editorial: Brand Europe. Where next?». Place Branding and Public Diplomacy, vol. 3, n 2, 115-119.

ANHOLT, S. (2005b): «Nation brand as context and reputation». Place Branding and Public Diplomacy, vol. 1, n $\mathrm{n}^{\mathrm{3}}$ 3, 224-228.

ANHOLT, S. (2002): «Nation brands: The value of 'provenance' in branding» en Destination branding: Creating unique destination proposition (Morgan, N., Pritchard, A. y Pride, R. eds.). Oxford, Elsevier, 42-56.

ANHOLT, S. y HILDRETH, J. (2004). Brand America: The mother of all brands. London. Cyan.

BAKER, B. (2007): Destination branding for small cities: The essentials for successful place branding. Portland. Creative Leap Books.

BLAIN, C. LEVY, S.E. y RITCHIE, B.J.R. (2005): «Destination branding: Insights and practices from destination management organizations». Journal of Travel Research, vol. $43, n^{\circ} 4,328-338$.

BLICHFELDT, B.S. (2005): «Unmanageable place brands?». Place Branding, vol. 1, $\mathrm{n}^{\circ} 4$, 388-401.

BRAMWELL, B. y RAWDING, L. (1996): «Tourism marketing images of industrial cities». Annals of Tourism Research, vol. 23, $\mathrm{n}^{\circ}$ 1, 201-221.

CAI, L.A. (2002): «Cooperative branding for rural destinations». Annals of Tourism Research, vol. 29, n 3, 720-742.

CAMPRUBÍ, R. (2011): «El rol del turista en la formación de la imagen turística emitida», en Manual de comunicación turística: De la información a la persuasión, de la promoción a la emoción (San Eugenio, J. coord.). Barcelona, Documenta Universitaria, 115124.

CAMPRUBÍ, R. (2009): La formació de la imatge turística induïda: el paper de les xarxes relacionals. Tesis doctoral. Girona. Universitat de Girona.

CARDÚS, S. (2010): «La identitat, reconeixement i diferenciació». Paradigmes, $\mathrm{n}^{\circ}$ 5, 17-23.

COHEN, E. y BUTLER, R.W. (1995): «Contemporary tourism, trends and challenges: sustainable authenticity or contrived post-modernity?», en Changes in Tourism: people, places, processes (Butler, R.W. y Pearce, D. eds.). London, Routledge, 12-29.

CROMPTON, J.L. (1979): «An assessment of the image of Mexico as a vacation destination and the influence of geographical location upon the image». Journal of Travel Research, vol. 17, $\mathrm{n}^{\circ} 4,18-23$.

DE CHERNATONY, L. y DALL'OLMO RILEY, F. (1998): «Defining a brand: Beyond the literature with experts interpretations». Journal of Marketing Management, vol. 14, $\mathrm{n}^{\circ} 5$, 417-443. 
DE UÑA, E. y VILLARINO, M. (2011): «Configuraciones de identidad en territorios del turismo. Condiciones generales en Galicia». Cuadernos de Turismo, $\mathrm{n}^{\circ}$ 27, 259-272.

DINNIE, K. (2011): City Branding: Theory and Cases. United Kingdom. Palgrave Macmillan.

DINNIE, K. (2008): Nation branding: Concepts, issues, practice, Butterworth-Heinemann. Oxford.

DOBNI, D. y ZINKHAN, G.M. (1990): «In Search of Brand Image: A Foundation Analysis», en Advances in Consumer Research (Goldberg, M.E., Gorn, G. y Pollay, R.W. eds.). Houston, Association for Consumer Research, 110-119.

DONAIRE, J.A. (2012): Turismo cultural, entre la experiencia y el ritual. Bellcaire d'Empordà. Vitel·la.

ECO, U. (1986): Viaje a la hiperrealidad. La estrategia de la ilusión. Barcelona. Lumen.

EVANS, G. (2003): «Hard-branding the cultural city: from Prado to Prada». International Journal of Urban and Regional Research, vol. 27, n 2, 417-440.

FERNÁNDEZ CAVIA, J. (2011): «Ciudades, regiones y países como marcas: luces y sombras del place branding», en Manual de comunicación turística: De la información a la persuasión, de la promoción a la emoción (San Eugenio, J. coord.). Barcelona, Documenta Universitaria, 103-113.

FREIRE, J. (2006): «Other tourists: A critical factor for a geo-brand-building process». Place Branding, vol. 2, $\mathrm{n}^{\circ}$ 1, 68-83.

GALÍ, N. y DONAIRE, J.A. (2006): «La imagen percibida por los turistas de la ciudad de Girona». Estudios Turísticos, $\mathrm{n}^{\circ} 168,123-139$.

GALÍ, N. y DONAIRE, J.A. (2005): «The social construction of the image of Girona: a methodological approach». Tourism Management, vol. 26, $\mathrm{n}^{\circ}$ 5, 777-785.

GALÍ, N. y DONAIRE, J.A. (2003): «La imagen a priori de los destinos turísticos monumentales: el caso de Girona». Papers de Turisme, $\mathrm{n}^{\circ}$ 34, 78-97.

GARAY, L. y CÀNOVES, G. (2011): «Life cycles, stages and tourism story. The Catalonia (Spain) experience». Annals of Tourism Research, vol. 38, nº 2, 651-671.

GOVERS, R. y GO, F. (2009): Place branding: Glocal, virtual and physical identities, constructed, imagined and experienced. Hampshire: Palgrave Macmillan.

GOVERS, R., GO, F. y KUMAR, K. (2007): «Promoting tourism destination image». Journal of Travel Research, vol. 46, $\mathrm{n}^{\circ} 15,15-23$.

HANKINSON, G. (2010): «Place branding theory: A cross-domain literature review from a marketing perspective» en Towards effective place brand management. Branding european cities and regions (Ashworth, G. y Kavaratzis, M., eds.). Northampton, Edward Elgar, 15-35.

HANKINSON, G. (2004): «Relational network brands: Towards a conceptual model of place brands». Journal of Vacation Marketing, vol. 10, nº 2, 109-121.

HUERTAS, A. (2011): «Las marcas turísticas de destinos», en Manual de comunicación turística: De la información a la persuasión, de la promoción a la emoción (San Eugenio, J. coord.). Barcelona, Documenta Universitaria, 75-84.

JENKINS, P. (2005): «Space, place and territory: An analytical framework» en Place identity, participation and planning (Hague, C. y Jenkins, P. eds.). London, Routledge, 19-37.

KAPFERER, J. (1994). La marca: Capital de la empresa. Barcelona. EDSA. 
KAVARATZIS, M. (2011): «The dishonest relationship between city marketing and culture: Reflections on the theory and the case of Budapest». Journal of Town \& City Management, vol. 1, no 4, 334-345.

KAVARATZIS, M. (2005): «Place branding: A review of trends and conceptual models». The Marketing Review, vol. 5, n 4, 329-342.

KAVARATZIS, M. (2004): «From city marketing to city branding: Towards a theoretical framework for developing city brands». Place Branding, vol. 1, nº 1, 58-73.

KOTLER, P. y GERTNER, D. (2002): «Country as brand, product, and beyond: A place marketing and brand management perspective». The Journal of Brand Management, vol. 9, nº 4, 249-261.

KOTLER, P., HAIDER, D.H. y REIN, I. (1994): Mercadotecnia de localidades. México. Diana.

LASH, S. y URRY, J. (1998): Economías de signos y espacio: sobre el capitalismo de la posorganización. Buenos Aires. Amorrortu.

LÓPEZ-LITA, R. y BENLLOCH, M.T. (2006): «¿Necesitamos marcas territorio?». Técnica económica, $\mathrm{n}^{\circ} 175,50-52$.

LÓPEZ-LITA, R. y BENLLOCH, M.T. (2005): «De la marca comercial a la marca territorio». Recerca: Revista de pensament $i$ anàlisi, $\mathrm{n}^{\circ}$ 5, 87-100.

MACCANNELL, D. (2003): El turista, una nueva teoría de la clase ociosa. Barcelona. Melusina.

MIOSSEC, J.M. (1977): «L'image touristique comme introduction à la géographie du tourisme». Annales de Géographie, vol. 86, nº 473, 55-70.

MONERRIS, A. (2008). Place branding: planteamientos y enfoques básicos. Disponible en: http://www.slideshare.net/Monerris/place-branding-planteamientos-y-enfoques-basicos

MORGAN, N., PRITCHARD, A. y PRIDE, R. (2002): «Introduction», en Destination branding: Creating unique destination proposition (Morgan, N., Pritchard, A. y Pride, R.. eds.). Oxford, Elsevier, 3-16.

MUÑOZ, F. (2008): Urbanalización. Paisajes comunes, lugares globales. Barcelona. Gustavo Gili.

NOGUÉ, J. y SAN EUGENIO, J. (2009): «Pensamiento geográfico versus teoría de la comunicación. Hacia un modelo de análisis comunicativo del paisaje». Documents d'Anàlisi Geogràfica, $\mathrm{n}^{\circ}$ 55, 27-55.

NOGUÉ, J. y ALBET, A. (2007): «Cartografía de los cambios sociales y culturales», en Geografía humana: Procesos, riesgos e incertidumbres en un mundo globalizado (Romero, J. coord.). Barcelona, Ariel, 173-219.

NOGUÉ, J. (1999): «El retorno al lugar. La creación de identidades territoriales». Claves de razón práctica, vol. 92, 9-11.

OLINS, W. (2004): Brand: Las marcas según Wally Olins. Madrid. Turner.

OLINS, W. (2002): «Branding the nation: the historical context». The Journal of Brand Management, vol. 9, $\mathrm{n}^{\circ}$ 4-5, 241-248.

OLINS, W. (1999): Trading identities: Why countries and companies are taking on each others' roles. London. Foreign Policy Centre.

OLLÉ, R., y RIU, D. (2009): El nuevo brand management: Cómo plantar marcas para hacer crecer negocios. Barcelona. Gestión 2000. 
PAPADOPOULOS, N. (2004): «Place branding: Evolution, meaning and implications». Place Branding, vol. 1, $\mathrm{n}^{\circ}$ 1, 36-49.

PARK, S.Y. y PETRICK, JF. (2006): «Destinations perspectives of branding». Annals of Tourism Research, vol. 33, $\mathrm{n}^{\circ}$ 1, 262-265.

PASQUINELLI, C. (2010): «The limits of Place Branding for Local Development. The case of Tuscany and Arnovalley Brand». Local Economy, vol. 25, n $^{\circ} 7,558-572$.

PRAT, J. y CÀNOVES, G. (2012): «La importancia del turismo cultural en los destinos consolidados. La Costa Brava y los Museos de Dalí». Palermo Business Review, $\mathrm{n}^{\circ} 6$, 125-143.

RIEZEBOS, R. (2003): Brand Management: A Theorical and Practical Approach. London. Prentice Hall.

RODRÍGUEZ-AMAT, J.R. y CAMPALANS, C. (2010): «Hacer país o vender país: del nationbuilding al country branding o viceversa», en Tourismes, Patrimoines, Identités, Territoires (Bataillou, C.J., ed.). Perpignan, Presses Universitaires de Perpignan, 179192.

SAN EUGENIO, J. (2012): Teoría y métodos para marcas de territorio. Barcelona. UOC.

SAN EUGENIO, J. (2011): La transformació de territoris en marques: el reconeixement i la diferenciació d'identitats espacials en temps postmoderns. Un estat de la qüestió. Tesis doctoral. Barcelona. Universitat Pompeu Fabra.

SEMPRINI, A. (1995): El marketing de la marca: Una aproximación semiótica. Barcelona. Paidós.

SOLSONA, J. (2008). «Las marcas-destino de turismo rural en España», en El turismo rural. Estructura económica y configuración territorial en España (Pulido, J.I., coord.). Madrid, Síntesis, 261-286.

STOCK, F. (2009): «Identity, image and brand: A conceptual framework». Place Branding and Public Diplomacy, vol. 5, $\mathrm{n}^{\circ} 2,118-125$.

TASCI, A.D. y KOZAC, M. (2006): «Destination brands vs destination images: Do we know what we mean?». Journal of Vacation Marketing, vol. 12, n 4, 299-317.

URRY, J. (2004): La mirada del turista. Lima. Universidad de San Martín de Porres.

WANG, N. (1999): «Rethinking authenticity in tourism experience». Annals of Tourism Research, vol. 26, n 2, 349-370.

WORLD TOURISM ORGANISATION (2009): Handbook on tourism destination branding: With an introduction by Simon Anholt. Madrid. Organización Mundial del Turismo.

XIFRA, J. (2010): «Relaciones públicas y nacionalismo: Una aproximación a la construcción nacional desde la perspectiva de las relaciones públicas». Trípodos, $\mathrm{n}^{\circ}$ 26, 117-132.

XIFRA, J. (2009): «Catalan public diplomacy, soft power, and noopolitik: A public relations approach to Catalonia's governance». Catalan Journal of Communication \& Cultural Studies, vol. 1, n ${ }^{\circ} 1,67-85$. 
